\title{
Loneliness and its association with health service utilization in people with a psychotic disorder
}

\author{
Johanna C. Badcock ${ }^{\mathrm{a}, \mathrm{b}, *}$, Patsy Di Prinzio ${ }^{\mathrm{c}}$, Anna Waterreus ${ }^{\mathrm{c}, \mathrm{d}}$, Amanda L. Neil ${ }^{\mathrm{e}}$, Vera A. Morgan ${ }^{\mathrm{c}, \mathrm{d}}$ \\ a School of Psychological Science, University of Western Australia, Perth 6009, Australia \\ b Perth Voices Clinic, Murdoch 6150, Australia \\ c Neuropsychiatric Epidemiology Research Unit, School of Population and Global Health, The University of Western Australia, Australia \\ d Centre for Clinical Research in Neuropsychiatry, Division of Psychiatry, Medical School, The University of Western Australia, Australia \\ e Menzies Institute for Medical Research, University of Tasmania, Hobart, Tasmania, Australia
}

\section{A R T I C L E I N F O}

\section{Article history:}

Received 3 April 2020

Received in revised form 26 May 2020

Accepted 26 May 2020

Available online $\mathrm{xxxx}$

\section{Keywords:}

Health care

Health service utilization

Psychotic disorders

Loneliness

\begin{abstract}
A B S T R A C T
Background: Loneliness is common in people with psychotic disorders and associated with reduced health and well-being. The relationship between loneliness in psychosis and health service use is unclear. This study examined whether loneliness predicts increased health care utilization in this population, independently of sociodemographics, health and functioning.

Methods: We used cross-sectional data from the Second Australian National Survey of Psychosis. Loneliness was assessed using a single-item question, rated on a 4-point scale (not lonely; lonely occasionally; some friends but lonely for company; socially isolated and lonely). Health service use (past 12-months) was measured by the number of general practitioner (GP), emergency department (ED) and outpatient visits, inpatient admissions, and home visits by mental health professionals. Frequent hospital users comprised those in the top $15 \%$ of users of at least two services.

Results: Negative binomial regression analysis showed that loneliness was associated with an increased number of GP visits, ED visits and inpatient admissions, only. Socially isolated and lonely survey participants were more than twice as likely $(\mathrm{OR}=2.6$ ) of being 'frequent users' compared to non-lonely responders. Following stringent adjustment for covariates, loneliness remained significantly associated with being a 'frequent user' and showed a non-significant trend to an increased number of GP visits and inpatient admissions.

Conclusions: Loneliness is a complex social and personal problem for people with psychosis, related to greater use of some health services. Better strategies for identifying and responding to loneliness in this population have the potential to increase well-being and contain health service utilization costs.
\end{abstract}

(c) 2020 Elsevier B.V. All rights reserved.

\section{Introduction}

Loneliness in the general community is associated with increased use of health services. For example, recent eWSSASvidence suggests that people who feel lonely and lacking social connectedness visit their general practitioners (GP) more often than those who are not lonely (Cruwys et al., 2018; see also Ellaway et al., 1999). A similar pattern of results has also been reported in people with psychotic disorders (Waterreus and Morgan, 2018). In fact, annual use of GP services by people with psychotic disorders has increased over the last decade, reflecting a shift from in-patient to community-based care (Raudino et al., 2014). However, more detailed investigation of this patient

* Corresponding author at: School of Psychological Science, 35 Stirling Highway, Perth 6009, Australia

E-mail address: johanna.badcock@uwa.edu.au (J.C. Badcock). population showed that frequent attenders (i.e. who consulted a GP 12 or more times in the previous year) were significantly more likely to be lonely and socially isolated than less frequent attenders (i.e. who visited a GP between 1 and 11 times) (Waterreus and Morgan, 2018). Such findings merit further investigation, for at least two reasons. First, frequent use of services places significant demands on clinicians' time and expertise to fully understand their patients' needs, which has policy and practice implications. However, assisting primary care providers to better understand the psychosocial (as well as the mental and physical health) needs of their patients with psychotic disorders may help in improving treatment and service referral pathways (Jones et al., 2015). Second, misunderstanding of the reasons associated with higher rates of service use could unintentionally fuel public, professional and internalized stigma of psychosis (Grandon et al., 2019; Vass et al., 2017; Wood et al., 2014). For example, if GPs do not consider loneliness as a possible reason for frequent health service use, this could 
reinforce stigmatizing attitudes (e.g., that people with psychosis are "weak-not sick", see Reavley et al., 2014) and result in clients not being referred for psychosocial treatment (Sullivan et al., 2015).

There are several reasons that could explain why people with psychotic disorders use GP or hospital services more often than the general population. For example, there is consistent evidence indicating that people with psychotic disorders experience elevated levels of physical morbidity and premature mortality (Morgan et al., 2014; Reininghaus et al., 2015). Frequent contact with health professionals could therefore reflect good management of people with complex needs. Prior evidence also indicates that loneliness in psychotic disorders is associated with poorer physical health (e.g. cardiometablic status; Badcock et al., 2019; Tremeau et al., 2016), social functioning (Stain et al., 2012) and mental health (e.g. symptom expression; Badcock et al., 2015; Chau et al., 2019; Eglit et al., 2018). Indeed, sociodemographic, diagnostic and treatment (e.g. medication) factors significantly predict health service use in people with mental disorder (Castillejos et al., 2018; Twomey et al., 2015). On the other hand, increased GP consultations may be more directly related to the experience of loneliness - which occurs when an individual's social needs are not being met. That is, increased visits to a GP by people with psychotic illness could be providing the social connection and support that is perceived to be missing (Lim et al., 2018). A similar explanation has been put forward to account for frequent GP attenders in the general community (Ellaway et al., 1999). However, such potential explanations for health service use associated with loneliness in psychosis have not been tested empirically. In addition, whether loneliness in psychosis is associated with increased use of other types of care (e.g. inpatient and outpatient services) has received limited investigation, though Chrostek and colleagues reported a positive correlation with inpatient admissions, even after adjusting for sociodemographic, clinical and psychosocial variables (Chrostek et al., 2016). A better understanding of these relationships could help to improve the integrated (psychosocial and medical) treatment and overall quality of care and outcomes for people with psychotic illness.

\subsection{Aims}

The aim of the current study was to examine whether loneliness is associated with increased health service utilization in people with psychotic disorders. In particular, the following questions were addressed: 1) Is loneliness associated with increased use of health services by people with psychosis, independent of established predictors (E.g., demographics, diagnosis, symptoms, functioning and physical health)? and 2) Is loneliness associated with different types of health service use (visits to GPs, outpatient clinics or emergency departments and inpatient admissions) in people with psychotic disorders?

\section{Material and methods}

\subsection{Study population}

Data were drawn from the second Australian National Survey of Psychosis $(N=1825)$, which was designed to estimate the treated prevalence of psychotic disorders in adults (18-64 years) in contact with public mental health services, and to describe their mental and physical health, cognitive functioning, substance use, and personal and social circumstances. Each participant undertook a 3- to 4-hour interview, which provided detailed information regarding participant's sociodemographic, clinical, psychological and psychosocial functioning and included a physical and mental health assessment, administered by a trained mental health professional. Full details of the study design, and summary tables of many of the variables collected, are described elsewhere (Morgan et al., 2014; Morgan et al., 2012).

\subsection{Assessment of health service utilization}

Participants were asked about frequency of all health service utilization in the past 12 months including (1) GP visits, (2) hospital emergency department attendance (ED), (3) inpatient admissions, (4) attendance at outpatients including community-based health clinics, and (5) home visits by mental health professionals. Frequencies for each of the individual components of these health service contacts, were truncated at 60 , (i.e. "60 $=60$ or more"). Those participants with a profile of high service use - those who were amongst the most frequent users (approximately top 15\%) of more than one type of hospital service - were identified as 'frequent hospital service users'.

\subsection{Assessment of loneliness}

Consistent with our previous work (Badcock et al., 2019; Badcock et al., 2015), loneliness was measured with a single question: "In the last 12 months have you felt lonely?" (Hawthorne et al., 1999). Responses were made using a 4-point scale: (1) I have plenty of friends and have not been lonely; 2) Although I have friends I have been lonely occasionally; 3 ) I have some friends but have been lonely for company; 4) I have felt socially isolated and lonely).

\subsection{Mental health symptom assessment and diagnostic classification}

Present state, past year and lifetime mental health symptoms were rated using the Diagnostic Interview for Psychosis (DIP; Castle et al., 2006). In the present study, symptoms reported as present in the past 12 months were used. Diagnostic classification was made by a computer algorithm, which maps DIP items onto the Operational Criteria (OPCRIT; McGuffin et al., 1991) checklist in accordance with ICD-10 criteria, yielding diagnoses which were categorized into two categories (non-affective psychosis: schizophrenia, schizoaffective disorder, delusional disorder and other non-organic psychosis; affective psychosis: bipolar, mania and depressive psychosis). Inter-rater reliability of this instrument is known to be good (see Castle et al., 2006; Morgan et al., 2014). A custom, composite index of the number of positive and negative symptoms was also calculated, representing the presence of any past year positive and negative symptoms (i.e. the sum of any hallucinations, any delusions, any subjective thought disorder, restricted affect, poverty of speech, diminished sense of purpose, curbed interests, diminished social drive, diminished emotional range. Score range 0-9).

\subsection{Physical health assessment}

The presence or absence of metabolic syndrome was determined using harmonized criteria as previously described by Alberti et al. (2009). Specifically, the presence of metabolic syndrome was defined as meeting three or more of the following five at-risk threshold criteria: (1) elevated waist circumference ( $\mathrm{cm})$; (2) elevated triglycerides; (3) reduced high-density lipoprotein (HDL) cholesterol; (4) elevated systolic or diastolic blood pressure and (5) elevated fasting glucose or receiving medication for hypertension, hyperlipidaemia or hyperglycaemia. People with no, or insufficient measures to determine metabolic syndrome $(n=474)$ were included as a third category. Measurement of height, weight, waist circumference and blood pressure was conducted by trained staff using standardized procedures (see Morgan et al., 2014 online Supplementary Methods).

\subsection{Additional measures}

Participants provided detailed information about their social and personal circumstances, including school completion, marital status, living arrangements including any periods of homelessness in the previous 12 months, and indigenous status (Aboriginal and Torres Strait Islander, ATSI). The Socio-Economic Index for Areas (SEIFA) Relative 
Disadvantage Index (Australian Bureau of Statistics, 2008) was used as a measure of socioeconomic status, by using the SEIFA quintile of a participant's residential area. The first quintile represented the most disadvantaged postcodes and the fifth quintile the least disadvantaged. Homelessness was coded Yes/No using the Australian Bureau of Statistics definition: primary homelessness: living on the streets, in parks, or in deserted buildings; secondary homelessness: living in temporary shelters such as refuge, emergency accommodation, or sleeping on friend's couch; or tertiary homelessness: private boarding room. The Multidimensional Scale of Independent Functioning (MSIF; Jaeger et al., 2003) was used to index functional disability/independence (ability to meet residential role responsibilities). MSIF scores were categorized as full, moderate or minimal based on whether participants met all/most, some, or minimal/no role expectations in the past four weeks. Prescribed medication used in the previous four weeks was recorded (Waterreus et al., 2012).

\subsection{Ethics approval}

The study was approved by institutional ethics committees at each of the seven study sites and all participants provided written informed consent.

\subsection{Data analysis}

Participants who screened positive for psychosis but did not meet full criteria for an ICD-10 psychotic disorder were excluded from the analyses $(N=177)$. An additional 45 participants did not provide a response to the Loneliness question and could not be included in analyses. A small number $(N=3)$ of participants were excluded due to insufficient covariate measures.

Descriptive statistics were calculated for covariates for each category of loneliness. The distributions of outcome variables (GP visits, ED visits, inpatient admissions, outpatient visits, home visits) were assessed using box plots. These outcome variables were modelled as counts using negative binomial regression. Each outcome variable was analysed separately, allowing for minimal exclusion of participants from one outcome analysis, due to missing values in another outcome measure. The bivariate relationships between each categorical or continuous covariate and each outcome were summarised by incident rate ratios (IRR) and 95\% confidence intervals, whilst relationships with the composite measure of 'frequent use of hospital services' were summarised by odds ratios (OR) and 95\% confidence intervals. The relationship between loneliness and each outcome variable was further assessed using multivariable models to adjust for all covariates. The additional variation in health service use explained by loneliness, above and beyond that explained by other covariates was assessed using chisquared tests. Analyses were conducted using Stata/SE v15.1.

\section{Results}

\subsection{Descriptive characteristics}

Box plot summaries of the distributions of the number of GP visits, ED visits, inpatient admissions, outpatient visits and home visits are presented in Fig. 1. All outcome variables were positively skewed, indicating that for each type of health care the majority of participants reported low levels of service use. In contrast, there were very few participants who reported the highest frequencies of service use. Two data points (ED visit value of 60 and inpatient admission value of 20) were excluded from further analyses to avoid disproportionate influence by single observations.

Based on natural cut points of the distributions in Fig. 1, participants who reported at least 2 Emergency Department presentations were considered frequent users of this service, participants who reported at least 2 Inpatient admissions were considered frequent Inpatients and

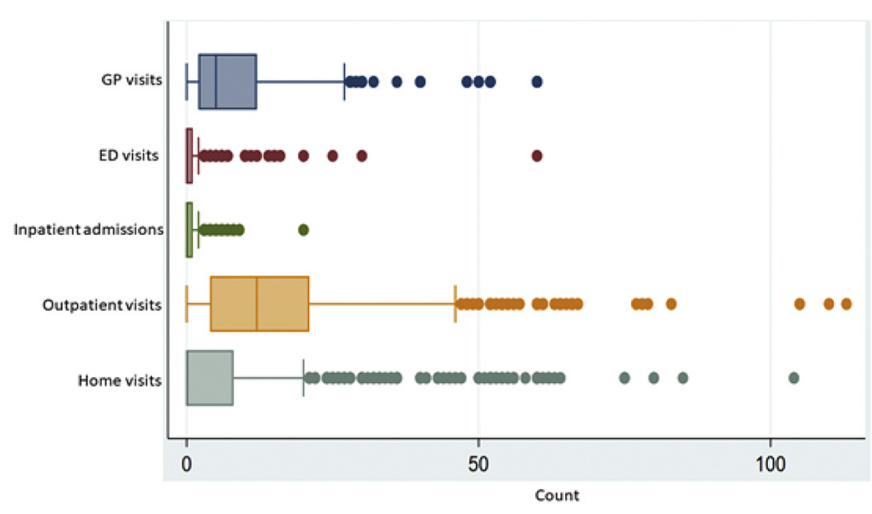

Fig. 1. Boxplot summaries of the distributions of health service use variables.

participants who reported at least 26 Outpatient attendances were considered frequent Outpatients. These cut points correspond to the top 15th percentiles of their respective distributions. A total of 194 (12.4\%) of participants satisfied at least 2 of these 3 'frequent user' conditions and were classified as frequent hospital service users. Descriptive summaries of all covariates (sociodemographic, clinical, health and functioning), by level of loneliness and for the total study sample $(N=1600)$ are shown in Table 1 . Most participants had a nonaffective psychotic disorder and were being treated with atypical antipsychotic medication. The majority were also single, living with others, and in the previous four weeks met full residential role responsibilities. Compared to 'Non-lonely' responders, those who reported being 'Socially Isolated and Lonely' were more often female, living alone, separated/divorced or widowed, and had had a period of homelessness in the past 12 months. Socially Isolated and Lonely survey respondents also tended to have an affective psychosis, a higher number of psychotic symptoms, be taking antidepressant, mood stabilisers and anxiolytic medications, and were more likely to meet threshold criteria for metabolic syndrome.

\subsection{Bivariate relationships}

Table 2 summarizes the pattern of relationships between loneliness, covariates and outcome variables. The results show that being socially isolated and lonely was significantly associated with an increased number of GP visits, ED visits and inpatient admissions, but not with the number of outpatient or home visits. The odds of being a 'frequent hospital service user' were 2.6 times greater in 'Socially isolated and Lonely' compared to 'Non-lonely' responders.

The pattern of relationships between sociodemographic, clinical, physical and functioning variables and outcome measures was mixed. In terms of sociodemographic variables, a significant, consistent association was observed between female gender and four (of the six) measures of health service use, but no associations were found for age, education or indigenous identity. For clinical variables, use of typical and atypical antipsychotics was strongly associated with an increased number of home visits and less so outpatient visits, whilst typical antipsychotic use only was associated with increased GP use. Similarly, the number of medications used was associated with increases in all outcome variables. For physical health, meeting criteria for metabolic syndrome was associated with a significant increase in GP visits only.

\subsection{Multivariable relationships}

The relationships between loneliness and health service use were assessed using multivariate models, which adjusted for all covariates. Loneliness parameters are shown in Table 3 along with significance tests. Loneliness parameters are presented again, along with all 
Table 1

Descriptive summary of covariates by loneliness category.

\begin{tabular}{|c|c|c|c|c|c|}
\hline & $\begin{array}{l}\text { Not lonely } \\
N=322\end{array}$ & $\begin{array}{l}\text { Lonely occasionally } \\
\qquad N=512\end{array}$ & $\begin{array}{l}\text { Some friends but have been lonely } \\
\qquad N=395\end{array}$ & $\begin{array}{l}\text { Socially isolated and lonely } \\
\qquad N=371\end{array}$ & $\begin{array}{c}\text { Total } \\
N=1600\end{array}$ \\
\hline Categorical covariates & $\mathrm{N}(\%)$ & $\mathrm{N}(\%)$ & $\mathrm{N}(\%)$ & $\mathrm{N}(\%)$ & $\mathrm{N}(\%)$ \\
\hline \multicolumn{6}{|l|}{ Sex } \\
\hline Male & $215(66.8)$ & $314(61.3)$ & $238(60.3)$ & $209(56.3)$ & $976(61.0)$ \\
\hline Female & $107(33.2)$ & $198(38.7)$ & $157(39.8)$ & $162(43.7)$ & $624(39.0)$ \\
\hline \multicolumn{6}{|l|}{ Education } \\
\hline Completed year 12 & $89(27.6)$ & $183(35.7)$ & $140(35.4)$ & $98(26.4)$ & 510 (31.9) \\
\hline \multicolumn{6}{|l|}{ Living arrangement } \\
\hline Lives with others & $235(73)$ & $349(68.2)$ & $244(61.8)$ & $246(66.3)$ & $1074(67.1)$ \\
\hline Lives alone & $83(25.8)$ & $150(29.3)$ & $143(36.2)$ & $117(31.5)$ & $493(30.8)$ \\
\hline Other* & $4(1.2)$ & $13(2.6)$ & $8(2.0)$ & $8(2.2)$ & $33(2.1)$ \\
\hline Any homelessness & $29(9.0)$ & $50(9.8)$ & $63(16.0)$ & $58(15.6)$ & $200(12.5)$ \\
\hline \multicolumn{6}{|l|}{ Marital status } \\
\hline Single & $220(68.3)$ & $328(64.1)$ & $243(61.5)$ & $218(58.8)$ & 1009 (63.1) \\
\hline Married/de facto & $54(16.8)$ & $91(17.8)$ & $60(15.2)$ & $62(16.7)$ & $267(16.7)$ \\
\hline Separated/divorced/widowed & $48(14.9)$ & $93(18.2)$ & $92(23.3)$ & $91(24.5)$ & $324(20.3)$ \\
\hline \multicolumn{6}{|l|}{ Socioeconomic status } \\
\hline 1 Most disadvantaged & $56(17.4)$ & $103(20.1)$ & $67(17)$ & $84(22.6)$ & $310(19.4)$ \\
\hline 2 & $68(21.1)$ & $98(19.1)$ & $80(20.3)$ & $71(19.1)$ & $317(19.8)$ \\
\hline 3 & $62(19.3)$ & $111(21.7)$ & $77(19.5)$ & $60(16.2)$ & $310(19.4)$ \\
\hline 4 & $76(23.6)$ & $92(18)$ & $88(22.3)$ & $78(21)$ & $334(20.9)$ \\
\hline 5 Least disadvantaged & $60(18.6)$ & $108(21.1)$ & $83(21)$ & $78(21)$ & $329(20.6)$ \\
\hline \multicolumn{6}{|l|}{ Indigenous identity } \\
\hline ATSI & $19(5.9)$ & $21(4.1)$ & $17(4.3)$ & $25(6.7)$ & $82(5.1)$ \\
\hline \multicolumn{6}{|l|}{ Diagnosis } \\
\hline Affective & $52(16.2)$ & $128(25)$ & $101(25.6)$ & $112(30.2)$ & $393(24.6)$ \\
\hline Non-affective & $270(83.9)$ & $384(75)$ & $294(74.4)$ & $259(69.8)$ & $1207(75.4)$ \\
\hline \multicolumn{6}{|l|}{ Medication used } \\
\hline Typical antipsychotics & $57(17.7)$ & $77(15)$ & $69(17.5)$ & $55(14.8)$ & $258(16.1)$ \\
\hline Atypical antipsychotics & $263(81.7)$ & 399 (77.9) & $297(75.2)$ & $281(75.7)$ & $1240(77.5)$ \\
\hline Antidepressants & $83(25.8)$ & $183(35.7)$ & $162(41)$ & $152(41)$ & $580(36.3)$ \\
\hline Mood stabilisers & $84(26.1)$ & $146(28.5)$ & $109(27.6)$ & $121(32.6)$ & $460(28.8)$ \\
\hline Anxiolytics & $48(14.9)$ & $65(12.7)$ & $69(17.5)$ & $97(26.2)$ & $279(17.4)$ \\
\hline \multicolumn{6}{|l|}{ Metabolic syndrome } \\
\hline Not met & $116(36)$ & $156(30.5)$ & $124(31.4)$ & $90(24.3)$ & $486(30.4)$ \\
\hline Met risk threshold & $127(39.4)$ & $212(41.4)$ & $183(46.3)$ & $181(48.8)$ & 703 (43.9) \\
\hline Insufficient data & $79(24.5)$ & $144(28.1)$ & $88(22.3)$ & $100(27)$ & $411(5.7)$ \\
\hline \multicolumn{6}{|l|}{ Functioning (MSIF) } \\
\hline Full & $204(63.4)$ & $379(74)$ & $267(67.6)$ & $221(59.6)$ & $1071(66.9)$ \\
\hline Moderate & $93(28.9)$ & 109 (21.3) & $110(27.9)$ & $114(30.7)$ & $426(26.6)$ \\
\hline Minimal & $25(7.8)$ & $24(4.7)$ & $18(4.6)$ & $36(9.7)$ & $103(6.4)$ \\
\hline Continuous covariates & $\mathrm{M}(\mathrm{SD})$ & $\mathrm{M}(\mathrm{SD})$ & $\mathrm{M}(\mathrm{SD})$ & $\mathrm{M}(\mathrm{SD})$ & $\mathrm{M}(\mathrm{SD})$ \\
\hline Age (years) & $37.5(11.4)$ & $37.8(11.1)$ & $38.0(10.7)$ & $39.5(11.0)$ & $38.2(11.0)$ \\
\hline Number of medications & $2.8(2.1)$ & $2.9(2.1)$ & $3(2.1)$ & $3.5(2.8)$ & $3.1(2.3)$ \\
\hline Number of positive and negative symptoms & $3.7(2.4)$ & $3.9(2.3)$ & $4.6(2.3)$ & $5.4(1.9)$ & $4.4(2.3)$ \\
\hline
\end{tabular}

Notes: * Denotes 'unknown' living arrangement or currently in hospital. ATSI = Aboriginal and Torres Strait Islander; MSIF = Multidimensional Scale of Independent Functioning.

covariates, in Supplementary Table 1. Chi-square tests showed some evidence $(p=.06)$ that loneliness accounts for variation in GP visits, after accounting for all other factors. Participants who indicated they felt socially isolated and lonely had $1.2(95 \% \mathrm{CI} 1-1.4)$ more GP visits than those who did not feel lonely. Similarly, there was a trend $(p=.08)$ for loneliness to be associated with inpatient admissions, once the influence of covariates was controlled. Compared to Non-lonely participants, those who felt socially isolated and lonely had 1.3 (95\% CI 1-1.6) more inpatient admissions. Finally, loneliness explained a significant degree of variation in 'frequent hospital service use' $(p=.03)$, once other factors were controlled for. However, there was no evidence to support that loneliness independently contributed to ED, outpatient or home visits.

\section{Discussion}

In the current study, people with psychotic disorders who reported feeling lonely and socially isolated were more than twice as likely $(\mathrm{OR}=2.6)$ to be frequent users of hospital health care services than non-lonely individuals. Furthermore, this association remained significant, though somewhat attenuated $(\mathrm{OR}=1.8)$, following stringent adjustment for a broad range of covariates that, in the literature, have been reliably linked to increased health service use. When examining health services individually, a similar though attenuated relationship was also observed between loneliness and an increased number of GP visits (IRR $=1.2$ ) and inpatient admissions (IRR $=1.3$ ) upon adjustment for covariates. In contrast, no significant associations were observed for attendance at ED or outpatient services, or for home visits, when adjusting for potential confounders. These findings add to previous evidence linking loneliness in psychosis to increased use of some - though not all - forms of health care services (Chrostek et al., 2016; Waterreus and Morgan, 2018). However, these previous studies showed these relationships, with either no adjustment, or adjusting for a more limited range of confounding factors. Thus, the current findings are important in demonstrating a link between feeling lonely and increased use of some types of health care services in people with psychotic disorder, independently of sociodemographic factors, clinical and health needs, and functional abilities.

Why might loneliness be related to increased use of health services? Previous evidence suggests that the pain of loneliness may serve an adaptive social function, prompting people to reach out and rebuild social ties (Cacioppo and Cacioppo, 2018b). Consistent with this line of reasoning, Cruwys et al. (2018) suggested that for lonely people, visiting a GP may be one of the few ways of connecting with another person, 
Table 2

Bivariate relationships between loneliness, covariates and health service use.

\begin{tabular}{|c|c|c|c|c|c|c|}
\hline & GP visits & ED visits & Inpatient admission & Outpatient visits & $\begin{array}{l}\text { Frequent hospital use } \\
\text { (Odds Ratio) }\end{array}$ & Home visits \\
\hline \multicolumn{7}{|l|}{ Loneliness } \\
\hline Not lonely & Reference & Reference & Reference & Reference & Reference & Reference \\
\hline Lonely occasionally & $1(0.9-1.2)$ & $1(0.8-1.3)$ & $1.2(0.9-1.4)$ & $1(0.9-1.2)$ & $1.6(1-2.8)$ & $0.8(0.6-1.2)$ \\
\hline Some friends, but lonely & $1.2(1-1.4)$ & $1(0.8-1.3)$ & $1.5(1.2-1.9)$ & $1.1(1-1.3)$ & $2.5(1.5-4.1)$ & $0.8(0.6-1.2)$ \\
\hline Socially isolated and lonely & $1.4(1.2-1.7)$ & $1.4(1.1-1.9)$ & $1.8(1.4-2.2)$ & $1(0.9-1.2)$ & $2.6(1.5-4.3)$ & $1.1(0.7-1.5)$ \\
\hline \multicolumn{7}{|l|}{ Categorical covariates } \\
\hline \multicolumn{7}{|l|}{ Sex } \\
\hline Male & Reference & Reference & Reference & Reference & Reference & Reference \\
\hline Female & $1.3(1.1-1.4)$ & $1.5(1.2-1.7)$ & $1.3(1.1-1.5)$ & $1.1(1-1.3)$ & $1.6(1.2-2.2)$ & $1.1(0.8-1.4)$ \\
\hline \multicolumn{7}{|l|}{ Education } \\
\hline Completed year 12 & $0.9(0.8-1)$ & $0.8(0.7-1)$ & $0.9(0.8-1.1)$ & $1.1(1-1.2)$ & $0.9(0.6-1.2)$ & $0.8(0.6-1)$ \\
\hline \multicolumn{7}{|l|}{ Living arrangement } \\
\hline Lives with others & Reference & Reference & Reference & Reference & Reference & Reference \\
\hline Lives alone & $1.2(1.1-1.3)$ & $0.9(0.7-1.1)$ & $0.9(0.8-1.1)$ & $1(0.9-1.2)$ & $1.2(0.9-1.7)$ & $1.1(0.8-1.4)$ \\
\hline Other* & $0.7(0.5-1.0)$ & $2.4(1.3-4.2)$ & $3.1(2.0-4.7)$ & $0.6(0.4-0.9)$ & $2.3(1-5.5)$ & $0.6(0.3-1.5)$ \\
\hline Any homelessness & $1(0.9-1.2)$ & $1.6(1.2-2)$ & $1.7(1.4-2.1)$ & $1.1(0.9-1.3)$ & $1.6(1.1-2.4)$ & $0.7(0.5-1)$ \\
\hline \multicolumn{7}{|l|}{ Marital status } \\
\hline Married & Reference & Reference & Reference & Reference & Reference & Reference \\
\hline Single & $1.2(1-1.4)$ & $0.7(0.6-0.9)$ & $0.8(0.6-0.9)$ & $1.2(1.1-1.4)$ & $0.6(0.4-0.8)$ & $1.5(1.1-2.1)$ \\
\hline Separated & $0.9(0.8-1)$ & $0.8(0.6-1.1)$ & $1(0.8-1.3)$ & $1.1(1-1.4)$ & $0.8(0.5-1.3)$ & $1.1(0.7-1.6)$ \\
\hline \multicolumn{7}{|l|}{ Socioeconomic status } \\
\hline 1 most disadvantage & Reference & Reference & Reference & Reference & Reference & Reference \\
\hline 2 & $0.8(0.7-0.9)$ & $0.7(0.5-0.9)$ & $0.5(0.4-0.7)$ & $1(0.9-1.2)$ & $0.4(0.2-0.6)$ & $1.1(0.8-1.7)$ \\
\hline 3 & $0.8(0.6-0.9)$ & $0.5(0.4-0.7)$ & $0.6(0.5-0.7)$ & $1(0.8-1.2)$ & $0.5(0.3-0.8)$ & $1.2(0.9-1.8)$ \\
\hline 4 & $0.9(0.8-1.1)$ & $0.6(0.4-0.8)$ & $0.7(0.5-0.8)$ & $1.1(0.9-1.3)$ & $0.7(0.4-1)$ & $1.2(0.8-1.7)$ \\
\hline 5 least disadvantage & $0.7(0.6-0.9)$ & $0.4(0.3-0.6)$ & $0.7(0.5-0.9)$ & $1.2(1-1.4)$ & $0.4(0.2-0.6)$ & $1.5(1-2.2)$ \\
\hline Indigenous identity & $1.2(0.9-1.5)$ & $1.3(0.9-1.9)$ & $1.3(0.9-1.8)$ & $0.9(0.7-1.2)$ & $1.7(0.9-3)$ & $1(0.6-1.8)$ \\
\hline \multicolumn{7}{|l|}{ Diagnosis } \\
\hline Affective & Reference & Reference & Reference & Reference & Reference & Reference \\
\hline Non-affective & $0.8(0.7-0.9)$ & $0.7(0.6-0.9)$ & $0.8(0.7-0.9)$ & $1(0.9-1.2)$ & $0.7(0.5-1)$ & $1.3(1-1.7)$ \\
\hline Typical antipsychotics & $1.2(1.1-1.4)$ & $1.3(1-1.6)$ & $1.1(0.9-1.3)$ & $1.2(1.1-1.4)$ & $1.2(0.8-1.8)$ & $1.6(1.2-2.2)$ \\
\hline Atypical antipsychotics & $0.9(0.8-1)$ & $0.8(0.7-1)$ & $1.1(0.9-1.3)$ & $1.2(1.1-1.4)$ & $1.1(0.8-1.6)$ & $1.4(1.1-1.9)$ \\
\hline Antidepressants & $1.4(1.2-1.5)$ & $1.4(1.2-1.7)$ & $1.1(1-1.3)$ & $1(0.9-1.2)$ & $1.7(1.2-2.3)$ & $1(0.8-1.2)$ \\
\hline Mood stabilisers & $1.3(1.2-1.5)$ & $1.2(1-1.5)$ & $1.2(1-1.4)$ & $1.1(0.9-1.2)$ & $1.5(1.1-2)$ & $1(0.7-1.2)$ \\
\hline Anxiolytics & $1.7(1.5-1.9)$ & $1.7(1.3-2.1)$ & $1.6(1.3-1.9)$ & $1.1(0.9-1.2)$ & $1.8(1.2-2.5)$ & $1(0.7-1.3)$ \\
\hline \multicolumn{7}{|l|}{ Metabolic syndrome } \\
\hline Not met & Reference & Reference & Reference & Reference & Reference & Reference \\
\hline Met risk threshold & $1.3(1.1-1.5)$ & $1(0.8-1.3)$ & $1(0.8-1.1)$ & $1(0.9-1.2)$ & $0.9(0.7-1.3)$ & $1.1(0.8-1.4)$ \\
\hline Insufficient data & $1(0.9-1.2)$ & $0.9(0.7-1.2)$ & $1(0.8-1.2)$ & $1(0.8-1.1)$ & $0.9(0.6-1.4)$ & $0.8(0.6-1.1)$ \\
\hline \multicolumn{7}{|l|}{ Functioning (MSIF) } \\
\hline Full & Reference & Reference & Reference & Reference & Reference & Reference \\
\hline Moderate & $1(0.9-1.2)$ & $1.5(1.2-1.8)$ & $1.4(1.2-1.6)$ & $1.1(1-1.3)$ & $1.6(1.2-2.3)$ & $1.6(1.2-2.1)$ \\
\hline Minimal & $1.2(0.9-1.4)$ & $1.9(1.3-2.6)$ & $1.9(1.4-2.4)$ & $0.8(0.6-1)$ & $1.9(1.1-3.3)$ & $1.3(0.8-2.1)$ \\
\hline \multicolumn{7}{|l|}{ Continuous covariates } \\
\hline Age $>18$ years & $1(1-1)$ & $1(1-1)$ & $1(1-1)$ & $1(1-1)$ & $1(1-1)$ & $1(1-1)$ \\
\hline Number of medications & $1.2(1.2-1.2)$ & $1.1(1.1-1.1)$ & $1.1(1.1-1.1)$ & $1(1-1.1)$ & $1.2(1.1-1.3)$ & $1(1-1.1)$ \\
\hline Number of positive \& negative symptoms & $1(1-1)$ & $1.1(1-1.1)$ & $1.1(1.1-1.2)$ & $1.1(1-1.1)$ & $1.1(1.1-1.2)$ & $1.1(1.1-1.2)$ \\
\hline
\end{tabular}

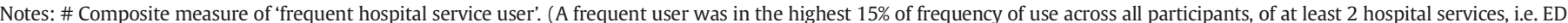

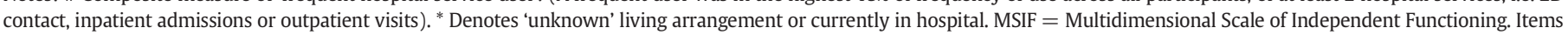
in bold represent alpha $=0.05$.

especially someone who is trusted to help. Whilst the current findings in people with psychotic disorder support a similar explanation - that increased health service use reflects a need for social connection in people who feel lonely - the cross-sectional nature of the study design means that the directionality of the association is unclear, and bidirectional effects remain possible. For example, frequent use of hospital services by people with psychotic disorders could lead to increased selfstigma, social distancing and/or withdrawal, and self-stigmatizing attitudes to mental illness have been associated with heightened feelings of loneliness in people with psychosis (Chrostek et al., 2016). Feelings of loneliness may also indirectly worsen psychotic symptoms making increased use of health services necessary (for a review see Badcock et al., 2020; Michalska da Rocha et al., 2017).

There is still much to be learned about loneliness in people with psychotic disorders (Lim et al., 2018). However, the high prevalence of loneliness, detrimental impact on mental and physical health, social functioning and well-being (Badcock et al., 2019; Nevarez-Flores,
2020; Stain et al., 2012), and increased use of health services suggests that loneliness can no longer be "stigmatized, ignored, or trivialized" (Cacioppo and Cacioppo, 2018a; p. 426); rather, they indicate that new approaches to treatment and appropriate models of care are required (Badcock et al., 2020; Lim et al., 2019). For example, it has recently been proposed that psychosocial variables, such as loneliness and social isolation, should be routinely included as primary care quality indicators in electronic health records (Matthews et al., 2016). Similarly, health practitioners are paying increased attention to 'social prescribing' (referring patients to community groups and activities, and voluntary services) as a solution to loneliness (Royal Australian College of General Practitioners and Consumers Health Forum, 2020). However, despite the potential benefits, social prescribing may carry risks of trivialising the experience and the difficulty of overcoming chronic loneliness (Brownlee and Jenkins, 2018). Furthermore, current evidence suggests that the most promising intervention for tackling loneliness involves cognitive modification (Mann et al., 2017); therefore, it is important 
Table 3

Significance of loneliness in multivariable models of health service use, adjusted for sociodemographic, clinical, health and functioning variables.

\begin{tabular}{|c|c|c|c|}
\hline Outcome variable & IRR (95\% CI) & \multicolumn{2}{|c|}{$\begin{array}{l}\text { Additional } \\
\text { variance } \\
\text { explained with } \\
\text { loneliness in } \\
\text { multivariable } \\
\text { model }\end{array}$} \\
\hline \multicolumn{4}{|l|}{ GP visits } \\
\hline \multicolumn{4}{|l|}{ Loneliness } \\
\hline Not lonely & Reference & & \\
\hline Lonely occasionally & $1(0.8-1.1)$ & Chi-sq & 7.33 \\
\hline Some friends but have been lonely & $1.1(0.9-1.3)$ & & 3 \\
\hline Socially isolated and lonely & $1.2(1-1.4)$ & $\mathrm{p}$ value & 0.06 \\
\hline \multicolumn{4}{|l|}{ ED visits } \\
\hline \multicolumn{4}{|l|}{ Loneliness } \\
\hline Not lonely & Reference & & \\
\hline Lonely occasionally & $1(0.8-1.3)$ & Chi-sq & 1.05 \\
\hline Some friends but have been lonely & $0.9(0.7-1.2)$ & df & 3 \\
\hline Socially isolated and lonely & $1(0.7-1.3)$ & $\mathrm{p}$ value & 0.78 \\
\hline \multicolumn{4}{|l|}{ Inpatient admissions } \\
\hline \multicolumn{4}{|l|}{ Loneliness } \\
\hline Not lonely & Reference & & \\
\hline Lonely occasionally & $1.1(0.9-1.4)$ & Chi-sq & 6.81 \\
\hline Some friends but have been lonely & $1.3(1-1.6)$ & & 3 \\
\hline Socially isolated and lonely & $1.3(1-1.6)$ & $\mathrm{p}$ value & 0.08 \\
\hline \multicolumn{4}{|l|}{ Outpatient visits } \\
\hline \multicolumn{4}{|l|}{ Loneliness } \\
\hline Not lonely & Reference & & \\
\hline Lonely occasionally & $1(0.8-1.1)$ & Chi-sq & 1.64 \\
\hline Some friends but have been lonely & $1(0.9-1.2)$ & df & 3 \\
\hline Socially isolated and lonely & $0.9(0.8-1.1)$ & p value & 0.65 \\
\hline Frequent hospital use $\mathrm{e}^{\#}$ & (Odds ratios) & & \\
\hline \multicolumn{4}{|l|}{ Loneliness } \\
\hline Not lonely & Reference & & \\
\hline Lonely occasionally & $1.6(0.9-2.7)$ & Chi-sq & 8.79 \\
\hline Some friends but have been lonely & $2.2(1.3-3.8)$ & df & 3 \\
\hline Socially isolated and lonely & $1.8(1-3.1)$ & $\mathrm{p}$ value & 0.03 \\
\hline \multicolumn{4}{|l|}{ Home visits } \\
\hline \multicolumn{4}{|l|}{ Loneliness } \\
\hline Not lonely & Reference & & \\
\hline Lonely occasionally & $0.9(0.6-1.3)$ & Chi-sq & 3.15 \\
\hline Some friends but have been lonely & $0.8(0.6-1.1)$ & df & 3 \\
\hline Socially isolated and lonely & $1(0.7-1.5)$ & $\mathrm{p}$ value & 0.37 \\
\hline
\end{tabular}

Notes: \# Composite measure of 'frequent hospital service user'. (A frequent user was in the highest $15 \%$ of frequency of use across all participants, of at least 2 hospital services, i.e. ED contact, inpatient admissions or outpatient visits).

to recognize that social prescribing is not a substitute for psychological therapy.

\subsection{Limitations and strengths}

The current findings need to be evaluated in light of both the strengths and limitations of the study. First, the outcome measure relied on self-reported health service use, which may have introduced error. Future studies would benefit from the use of both subjective and objective indices of service use. A second potential weakness is that the assessment of loneliness relied on a single-item measure which may have limited reliability compared to multi-item tools. Whilst recent evidence suggests that single-item measures of loneliness may yield a similar pattern of associations with psychosis as those obtained with more comprehensive measures (Michalska da Rocha et al., 2017) it is important that the current findings (specifically related to health service use) are interpreted cautiously. Our single item measure also incorporates the experience of objective social isolation along with feelings of loneliness, which may temper the conclusion that loneliness is associated to health service use. Partly countering this concern, the multivariable analysis (see Supplementary Table) included objective social circumstances (e.g. living alone/others; marital status single/married) as covariates. The results of these analyses therefore lend some strength to the conclusion that loneliness may be particularly relevant to 'frequent hospital service use' ( $p=.03$ ), once these (and other) factors were controlled for. However, future studies would benefit from using measures that help to disentangle the specific contribution of subjective feelings of loneliness versus objective social isolation to health service use in people with psychosis. Similarly, the study employed a crosssectional design. Further research needs to expand on these findings by using a longitudinal design, which would allow researchers to track whether loneliness follows, coincides with, or precedes, health service use. Finally, the costs associated with loneliness and health service use in people with psychosis were not addressed. Alternatively, though our sample does not include people with psychosis not seeing services at all in the past 12 months, or only in contact with GP or private services, it is a representatively drawn sample of all who were in contact over a one year period with public treatment services, including a diverse range of ages, levels of chronicity, and diagnostic categories.

\subsection{Conclusion}

The findings of our study are important for policy and planning of health care services, in highlighting the need to recognize, and respond to, the psychological and social needs of people with psychotic illness. As feeling lonely and socially isolated almost doubles the odds of an individual being a frequent user of hospital health care services compared with not being lonely, strategies for identifying and responding to loneliness in this population have the potential to increase well-being and contain health service utilization costs.

Supplementary data to this article can be found online at https://doi. org/10.1016/j.schres.2020.05.059.

\section{Declaration of competing interest \\ None.}

\section{Acknowledgements}

This publication is based on data collected in the framework of the 2010 Australian National Survey of High Impact Psychosis. The members of the Survey of High Impact Psychosis Study Group at the time of the Survey were as follows: V Morgan (Project Director); A Jablensky (Chief Scientific Advisor); A Waterreus (Project Coordinator); A Mackinnon (Statistician); R Bush, D Castle, M Cohen, C Galletly, C Harvey, P McGorry, J McGrath, and H Stain (Site Directors); V Carr (Australian Schizophrenia Research Bank); A Neil (Health Economics); B Hocking (SANE Australia); and S Saw (Australian Government Department of Health and Ageing). This report acknowledges, with thanks, the hundreds of mental health professionals who participated in the preparation and conduct of the survey and the many Australians with psychotic disorders and their GPs who gave their time and whose responses form the basis of this publication.

\section{Role of funding source}

This work was funded by the Australian Government Department of Health and Ageing. The funding agency had no further role in the study design, in the collection, analysis and interpretation of data; in the writing of the manuscript; or in the decision to submit the manuscript for publication.

\section{Ethical standard}

The authors assert that all procedures contributing to this work comply with the ethical standards of the relevant national and institutional committees on human experimentation and with the Helsinki Declaration of 1975, as revised in 2008.

\section{Contributors}

JCB conceived the study design, planned analyses and wrote the first draft of the manuscript.

PD and AW prepared the dataset and conducted the statistical analyses. AN assisted with interpretation of health service use data. VM provided expertise and guidance at all stages of the project. All authors contributed to revisions of the manuscript and approved the final version for publication.

\section{References}

Alberti, K.G., Eckel, R.H., Grundy, S.M., Zimmet, P.Z., Cleeman, J.I., Donato, K.A., Fruchart J.C., James, W.P., Loria, C.M., Smith Jr., S.C., International Diabetes Federation Task Force on, E, Prevention, Hational Heart, L, Blood, I, American Heart, A, World Heart, 
F., International Atherosclerosis, S, International Association for the Study of, O, 2009. Harmonizing the metabolic syndrome: a joint interim statement of the International Diabetes Federation Task Force on Epidemiology and Prevention; National Heart, Lung, and Blood Institute; American Heart Association; World Heart Federation; International Atherosclerosis Society; and International Association for the Study of obesity. Circulation 120 (16), 1640-1645.

Australian Bureau of Statistics, 2008. Socio-Economic Indexes for Areas (SEIFA) - 401 Technical Paper 2006. Catalogue No. 2039.0.55.001. Australian Bureau of Statistics, Canberra.

Badcock, J.C., Shah, S., Mackinnon, A., Stain, H.J., Galletly, C., Jablensky, A., Morgan, V.A., 2015. Loneliness in psychotic disorders and its association with cognitive function and symptom profile. Schizophr. Res. 169 (1-3), 268-273.

Badcock, J.C., Mackinnon, A., Waterreus, A., Watts, G.F., Castle, D., McGrath, J.J., Morgan, V.A., 2019. Loneliness in psychotic illness and its association with cardiometabolic disorders. Schizophr. Res. 204, 90-95.

Badcock, J.C., Adery, L.H., Park, S., 2020. Loneliness in psychosis: a practical review and critique for clinicians. Clin. Psychol. Sci. Pract. https://doi.org/10.1111/cpsp.12345 e12345.

Brownlee, K., Jenkins, D., 2018. Prescribing social activities to lonely people prompts ethical questions for GPs. Conversation accessed 21/08/19. https://theconversation.com/ prescribing-social-activities-to-lonely-people-prompts-ethical-questions-for-gps105439.

Cacioppo, J.T., Cacioppo, S., 2018a. The growing problem of loneliness. Lancet 391 (10119), 426.

Cacioppo, J.T., Cacioppo, S., 2018b. Loneliness in the modern age: an evolutionary theory of loneliness (ETL). In: Olson, J.M. (Ed.), Adv. Exp. Soc. Psychol. Academic Press, pp. 127-197.

Castillejos, M.C., Martin-Perez, C., Mayoral-Cleries, F., Bordallo-Aragon, A., SepulvedaMunoz, J., Moreno-Kustner, B., 2018. Factors associated with visits to general practitioners in patients with schizophrenia in Malaga. BMC Fam. Pract. 19 (1), 180.

Castle, D.J., Jablensky, A., McGrath, J.J., Carr, V., Morgan, V., Waterreus, A., Valuri, G., Stain, H., McGuffin, P., Farmer, A., 2006. The diagnostic interview for psychoses (DIP): development, reliability and applications. Psychol. Med. 36 (1), 69-80.

Chau, A.K.C., Zhu, C., So, S.H., 2019. Loneliness and the psychosis continuum: a metaanalysis on positive psychotic experiences and a meta-analysis on negative psychotic experiences. Int. Rev. Psychiatry 1-20.

Chrostek, A., Grygiel, P., Anczewska, M., Wciorka, J., Switaj, P., 2016. The intensity and correlates of the feelings of loneliness in people with psychosis. Compr. Psychiatry 70, 190-199.

Cruwys, T., Wakefield, J.R.H., Sani, F., Dingle, G.A., Jetten, J., 2018. Social isolation predicts frequent attendance in primary care. Ann. Behav. Med. 52 (10), 817-829.

Eglit, G.M.L., Palmer, B.W., Martin, A.S., Tu, X., Jeste, D.V., 2018. Loneliness in schizophrenia: construct clarification, measurement, and clinical relevance. PLoS One 13 (3), e0194021.

Ellaway, A., Wood, S., Macintyre, S., 1999. Someone to talk to? The role of loneliness as a factor in the frequency of GP consultations. Br. J. Gen. Pract. 49 (442), 363-367.

Grandon, P., Saldivia, S., Vaccari, P., Ramirez-Vielma, R., Victoriano, V., Zambrano, C., Ortiz, C., Cova, F., 2019. An integrative program to reduce stigma in primary healthcare workers toward people with diagnosis of severe mental disorders: a protocol for a randomized controlled trial. Frontiers Psychiatry 10, 110.

Hawthorne, G., Richardson, J., Osborne, R., 1999. The assessment of quality of life (AQoLL) instrument: a psychometric measure of health related quality of life. Qual. Life Res. 8, 209-224.

Jaeger, J., Berns, S.M., Czobor, P., 2003. The multidimensional scale of independent functioning: a new instrument for measuring functional disability in psychiatric populations. Schizophr. Bull. 29 (1), 153-168.

Jones, R., Major, B., Fear, C., 2015. Schizophrenia in a primary care setting. Curr. Psychiatry Rep. 17 (10), 84.

Lim, M.H., Gleeson, J.F.M., Alvarez-Jimenez, M., Penn, D.L., 2018. Loneliness in psychosis: a systematic review. Soc. Psychiatry Psychiatr. Epidemiol. 53 (3), 221-238.

Lim, M.H., Penn, D.L., Thomas, N., Gleeson, J.F.M., 2019. Is loneliness a feasible treatment target in psychosis? Soc. Psychiatry Psychiatr. Epidemiol. https://doi.org/10.1007/ s00127-00019-01731-00129.

Mann, F., Bone, J.K., Lloyd-Evans, B., Frerichs, J., Pinfold, V., Ma, R., Wang, J., Johnson, S. 2017. A life less lonely: the state of the art in interventions to reduce loneliness in people with mental health problems. Soc. Psychiatry Psychiatr. Epidemiol. 52 (6), 627-638.

Matthews, K.A., Adler, N.E., Forrest, C.B., Stead, W.W., 2016. Collecting psychosocial "vital signs" in electronic health records: why now? What are they? What's new for psychology? Am. Psychol. 71 (6), 497-504.

McGuffin, P., Farmer, A., Harvey, I., 1991. A polydiagnostic application of operational criteria in studies of psychotic illness: development and reliability of the opcrit system. Arch. Gen. Psychiatry 48 (8), 764-770.

Michalska da Rocha, B., Rhodes, S., Vasilopoulou, E., Hutton, P., 2018. Loneliness in psychosis: a meta-analytical review. Schizophr. Bull. 44 (1), 114-125. https://doi.org/ $10.1093 / \mathrm{schbul} / \mathrm{sbx} 036$

Morgan, V.A., Waterreus, A., Jablensky, A., Mackinnon, A., McGrath, J.J., Carr, V., Bush, R., Castle, D., Cohen, M., Harvey, C., Galletly, C., Stain, H.J., Neil, A.L., McGorry, P., Hocking, B., Shah, S., Saw, S., 2012. People living with psychotic illness in 2010: the second Australian national survey of psychosis. Aust. N. Z. J. Psychiatry 46 (8), 735-752.

Morgan, V.A., McGrath, J.J., Jablensky, A., Badcock, J.C., Waterreus, A., Bush, R., Carr, V., Castle, D., Cohen, M., Galletly, C., Harvey, C., Hocking, B., McGorry, P., Neil, A.L., Saw, S., Shah, S., Stain, H.J., Mackinnon, A., 2014. Psychosis prevalence and physical, metabolic and cognitive co-morbidity: data from the second Australian national survey of psychosis. Psychol. Med. 44 (10), 2163-2176.

Nevarez-Flores, A., 2020. Quality of Life in People with Psychotic Disorders: The Relationship with Global Functioning and its Predictors. University of Tasmania.

Raudino, A., Carr, V.J., Bush, R., Saw, S., Burgess, P., Morgan, V.A., 2014. Patterns of service utilisation in psychosis: findings of the 2010 Australian national survey of psychosis. Aust. N. Z. J. Psychiatry 48 (4), 341-351.

Reavley, N.J., Mackinnon, A.J., Morgan, A.J., Jorm, A.F., 2014. Stigmatising attitudes towards people with mental disorders: a comparison of Australian health professionals with the general community. Aust. N. Z. J. Psychiatry 48 (5), 433-441.

Reininghaus, U., Dutta, R., Dazzan, P., Doody, G.A., Fearon, P., Lappin, J., Heslin, M., Onyejiaka, A., Donoghue, K., Lomas, B., Kirkbride, J.B., Murray, R.M., Croudace, T., Morgan, C., Jones, P.B., 2015. Mortality in schizophrenia and other psychoses: a 10year follow-up of the SOP first-episode cohort. Schizophr. Bull. 41 (3), 664-673.

Royal Australian College of General Practitioners and Consumers Health Forum, 2020. Social Prescribing Roundtable, November 2019. pp. 1-17.

Stain, H.J., Galletly, C.A., Clark, S., Wilson, J., Killen, E.A., Anthes, L., Campbell, L.E., Hanlon, M., Harvey, C., 2012. Understanding the social costs of psychosis: the experience of adults affected by psychosis identified within the second Australian national survey of psychosis. Aust. N. Z. J. Psychiatry 46 (9), 879-889.

Sullivan, G., Mittal, D., Reaves, C.M., Haynes, T.F., Han, X., Mukherjee, S., Morris, S., Marsh, L., Corrigan, P.W., 2015. Influence of schizophrenia diagnosis on providers' practice decisions. J. Clin. Psychiatry 76 (8), 1068-1074 (quiz 1074).

Tremeau, F., Antonius, D., Malaspina, D., Goff, D.C., Javitt, D.C., 2016. Loneliness in schizophrenia and its possible correlates. An exploratory study. Psychiatry Res. 246, 211-217.

Twomey, C.D., Baldwin, D.S., Hopfe, M., Cieza, A., 2015. A systematic review of the predictors of health service utilisation by adults with mental disorders in the UK. BMJ Open 5 (7), e007575

Vass, V., Sitko, K., West, S., Bentall, R.P., 2017. How stigma gets under the skin: the role of stigma, self-stigma and self-esteem in subjective recovery from psychosis. PsychosisPsychological Soc. Integrative Approaches 9 (3), 235-244.

Waterreus, A., Morgan, V.A., 2018. Treating body, treating mind: the experiences of people with psychotic disorders and their general practitioners - findings from the Australian National Survey of High Impact Psychosis. Aust. N. Z. J. Psychiatry 52 (6), 561-572.

Waterreus, A., Morgan, V.A., Castle, D., Galletly, C., Jablensky, A., Di Prinzio, P., Shah, S., 2012. Medication for psychosis-consumption and consequences: the second Australian national survey of psychosis. Aust. N. Z. J. Psychiatry 46 (8), 762-773.

Wood, L., Birtel, M., Alsawy, S., Pyle, M., Morrison, A., 2014. Public perceptions of stigma towards people with schizophrenia, depression, and anxiety. Psychiatry Res. 220 $(1-2), 604-608$ 